\title{
BMJ Open Comparison between Custodiol, del Nido and modified del Nido in the myocardial protection - Cardioplegia Trial: a study protocol for a randomised, double-blind clinical trial
}

\author{
Adriana Silveira Almeida (D) ,, ${ }^{1,2}$ Rafael Oliveira Ceron (D) , ${ }^{1}$ Fernando Anschau (D) , \\ Luciane Kopittke (D) , ${ }^{2}$ Kathize Betti Lira (D) , ${ }^{1}$ Renan Senandes Delvaux (D) , \\ Juarez Rode (1) , ${ }^{1}$ Rafael Antônio Widholzer Rey (1) , ${ }^{1}$ Estefânia Inês Wittke (D) ," \\ Alfeu Roberto Rombaldi (iD) ${ }^{1}$
}

To cite: Almeida AS, Ceron RO, Anschau F, et al. Comparison between Custodiol, del Nido and modified del Nido in the myocardial protection - Cardioplegia Trial: a study protocol for a randomised, double-blind clinical trial. BMJ Open 2021;11:e047942. doi:10.1136/ bmjopen-2020-047942

- Prepublication history and additional supplemental material for this paper are available online. To view these files, please visit the journal online (http://dx.doi.org/10.1136/ bmjopen-2020-047942).

Received 15 December 2020 Accepted 20 August 2021

Check for updates

(c) Author(s) (or their employer(s)) 2021. Re-use permitted under CC BY-NC. No commercial re-use. See rights and permissions. Published by BMJ.

${ }^{1}$ Cardiothoracic Surgery Division, Hospital Nossa Senhora da Conceição, Porto Alegre, Rio Grande do Sul, Brazil ${ }^{2}$ Health Technology Assessment Center (NATS) and Education and Research Center (GEP), Hospital Nossa Senhora da Conceição, Porto Alegre, Rio Grande do Sul, Brazil

Correspondence to Dr Adriana Silveira Almeida; adrianasdealmeida@gmail.com

\section{ABSTRACT}

Introduction Myocardial protection is essential for successful cardiac surgery, and the search for an ideal cardioplegic solution has continued since its beginning. In this context, Custodiol, del Nido and modified del Nido are single-dose cardioplegic solutions with good safety profiles and great relevance in modern surgical practice. While these solutions have all been evaluated for their impact on patient outcomes independently, limited research exists comparing them directly. Thus, the present study aims to examine the effects of these cardioplegic solutions on myocardial protection and clinical outcomes in adult patients undergoing elective cardiac surgery. The assessment of the increase in myocardial injury biomarkers in patients submitted to all treatment methods may be considered a major strength of our study. Methods and analysis This is a clinical trial study protocol that will compare myocardial protection and clinical outcomes among three patient groups based on which cardioplegic solution was used. Patients will be randomised to receive del Nido $(n=30)$, modified del Nido $(n=30)$ or Custodiol $(n=30)$. Myocardial injury biomarkers will be measured at the baseline and 2 hours, 12 hours and 24 hours after the cardiopulmonary bypass. Clinical outcomes will be assessed during the trans operative period and the intensive care unit stay, in addition to other haematological parameters.

Ethics and dissemination This protocol and its related documents were approved by the Research Ethics

Committee of the Hospital Nossa Senhora da Conceição, Brazil, registered under no. 4.029.545. The findings of this study will be published in a peer-reviewed journal in the related field.

Trial registration number $\mathrm{RBR}-7 \mathrm{~g} 5 \mathrm{~s} 66$.

\section{INTRODUCTION}

Cardiac surgery procedures usually involve using cardiopulmonary bypass (CPB) and cardiac arrest, and, in consequence, myocardial protection is essential. ${ }^{1}$ Failure
Strengths and limitations of this study

- This is one of the first prospective randomised clinical trials comparing myocardial damage and clinical outcomes between Custodiol, del Nido and modified del Nido cardioplegic solutions.

- The assessment of the increase in myocardial injury biomarkers in patients submitted to all treatment methods may be considered a major strength of our study.

- The broad inclusion criteria will increase generalisability and may also make it possible to evaluate subgroups of interest.

- This trial will be performed at a single centre.

- This is a study with an insufficient sample for rare events.

to adequately protect the heart may lead to severe adverse consequences, including myocardial infarction (MI), ischaemiareperfusion injury and low-output cardiac syndrome. Such complications are associated with more extended stays in the intensive care unit (ICU), congestive heart failure and increased perioperative mortality. ${ }^{2}$

Cardioplegia is a fundamental component in providing heart protection, limiting metabolic activity and increasing the myocardium's capacity to resist ischaemia for prolonged periods, thus being essential for good surgical outcomes. Seeking an ideal solution, long-acting cardioplegic solutions were introduced $^{3}$ with two primary benefits: (1) in more complex or minimally invasive cardiac surgeries, the application of cardioplegia in a single dose avoids procedure interruptions, reducing the aortic cross-clamping time $\mathrm{e}^{34}$ and (2) patients submitted to cardiac surgery 
still suffer from postoperative cardiac dysfunction, with it being postulated that single-dose cardioplegia would protect the heart more effectively. ${ }^{3}$

The histidine-tryptophan-ketoglutarate solution or Custodiol (Essential Pharmaceuticals, Ewing, New Jersey, USA) was described by Bretschneider in the $1970 \mathrm{~s}^{5}$ and conceived as an alternative to hyperkalaemic crystalloid cardioplegic solutions ${ }^{67}$ used by some centres for myocardial protection in complex cardiac surgery and for organ preservation in transplant surgery. ${ }^{8}$ The del Nido cardioplegia was developed by Pedro del Nido and his team at the University of Pittsburgh in the 1990s, ${ }^{1}{ }^{10}$ having been used since 1994 for paediatric cardiac surgery at the Boston Children's Hospital and also used successfully in adults since 2003. ${ }^{11-16}$ The base solution for del Nido cardioplegia is usually Plasma-Lyte A (Baxter Healthcare Corporation, Deerfield, Illinois, USA), which has an electrolyte composition similar to the extracellular fluid and is calcium-free. More recently, some authors have advocated ${ }^{17}$ the use of traditional del Nido cardioplegia ingredients added to lactated Ringer's solution, as the base solution provided either similar or superior myocardial protection than the blood cardioplegia strategy. Both, Custodiol and del Nido, be it traditional or modified, are associated with safe single-dose administration and capable of proper myocardial protection for prolonged periods during ischaemia in $\mathrm{CPB}$, allowing the performance of uninterrupted procedures. ${ }^{3} 810$ 18-21

Thus far, there are no guidelines regarding using of a specific solution, and the literature does not confirm the superiority of one over the others. ${ }^{1}$ The standardisation of the method or ideal type of cardioplegic solution remains controversial due to the scarcity of studies clearly outlining the advantages and disadvantages of the available solutions. While each of these solutions has been evaluated for their impact on patient outcomes independently, limited research is available comparing them directly. Thus, the present study aims to examine the effects of Custodiol and traditional or modified del Nido, cardioplegic solutions, all with good safety profiles and great relevance in modern surgical practice, on myocardial protection and clinical outcomes in patients undergoing cardiac surgery.

\section{METHODS AND ANALYSIS}

The study protocol was developed following the Standard Protocol Items: Recommendations for Interventional Trials checklist, ${ }^{22}$ provided in online supplemental file 1. This study's approach will be based on the Consolidated Standards of Reporting Trials. ${ }^{23}$

\section{Study design}

A randomised, double-blinded, clinical trial study will be carried out at the Hospital Nossa Senhora da Conceição, a tertiary referral hospital in Cardiovascular Surgery in southern Brazil, to compare the effects of cardioplegic solutions-Custodiol, del Nido and modified del Nidoon myocardial protection and perioperative outcomes. The study design is shown in figure 1 .

\section{Patient and public involvement statement}

The patients or the public will not be involved in the design, recruitment or conduction of the study.

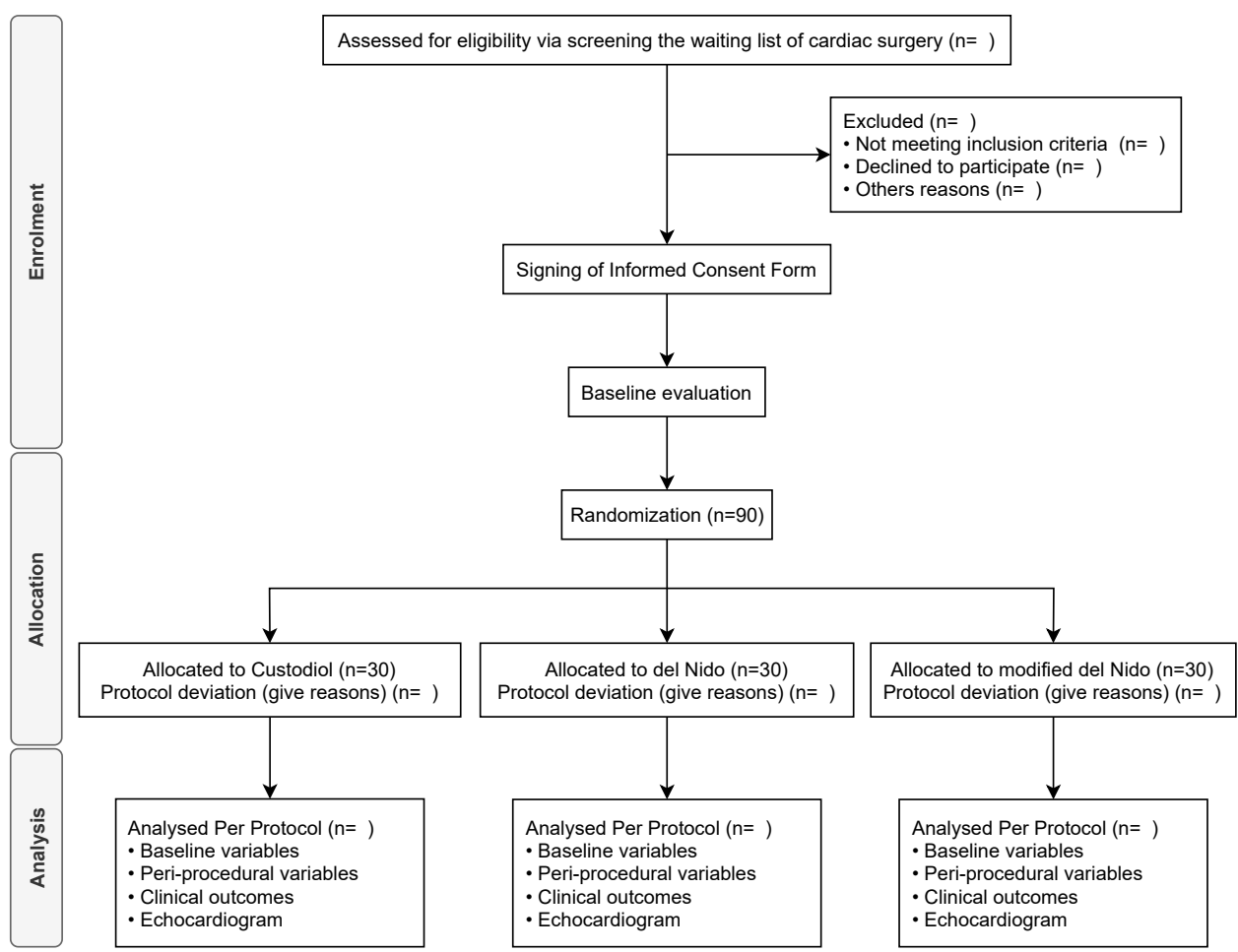

Figure 1 Consort diagram: flow of the participants throughout the study. 


\section{Eligibility criteria}

Subject inclusion and exclusion criteria are defined as follows. The study centre was chosen by convenience, and the eligibility criteria were defined a priori by care providers.

Patients referred for elective valve replacement surgery or coronary artery bypass grafting surgery aged at least 18 years will be enrolled. Patients with chronic renal disease (previous medical diagnosis or serum creatinine greater than $1.5 \mathrm{mg} / \mathrm{dL}$ ), previous cardiac surgery, severe psychiatric illness, or inability or unwillingness to give informed consent for participation will be excluded.

\section{Interventions}

Adult patients undergoing elective myocardial revascularisation surgery or valve replacement will be randomised to receive cardioplegic solutions del Nido (using PlasmaLyte $\mathrm{A}$ as the base solution), modified del Nido (using lactated Ringer's as the base solution) or Custodiol during CPB. They will be followed up for evaluating the effectiveness of the treatments initially proposed.

\section{Surgical technique}

Conventional general anaesthesia will be used for all patients. The surgical approach will be via median sternotomy. The CPB will be established by an arterial cannula in the ascending aorta or femoral artery. Venous drainage will be obtained via a two-stage cannula in the right atrium or bicaval cannulation through the superior and inferior vena cavae or femoral vein. Under CPB and aortic cross-clamping, cardioplegic arrest will be induced.

\section{Myocardial protection: preparation and handling of the solutions}

The cardioplegic solutions will be administered anterogradely, at the root of the aorta or coronary ostia, as per specific indication.

All solutions will be prepared by the perfusionist, the professional responsible for conducting $\mathrm{CPB}$, according to the standardised aseptic techniques routinised in the Cardiovascular Surgery Service, without any difference from what was habitually used before the beginning of the study since these solutions are already standardised and correctly employed at the institution.

Custodiol cardioplegia is a sterile prepackaged solution that does not require preparation since it comes ready for infusion. The composition of this solution may be observed in table $1 .^{8}$ This solution will be administered in a single dose of $25 \mathrm{~mL} / \mathrm{kg}$ over $6-8 \mathrm{~min}$ at a temperature of $4^{\circ} \mathrm{C}-8^{\circ} \mathrm{C}$ with a perfusion pressure of $150-200 \mathrm{~mm} \mathrm{Hg}$ and the possibility of an additional dose only after 3 hours of the first.

The del Nido and modified del Nido solutions will be manipulated at the Service moments before their administration, and either Plasma-Lyte A or the lactated Ringer's solution (modified del Nido) was used as the crystalloid base. The crystalloid:autologous blood ratio is $4: 1$. The composition made into a protocol at the Institution may also be observed in table 2. The solutions

\begin{tabular}{ll}
\hline \multicolumn{2}{l}{ Table 1 Custodiol composition } \\
\hline \multicolumn{2}{l}{ Composition } \\
\hline Sodium chloride & $15.0 \mathrm{mmol} / \mathrm{L}$ \\
\hline Potassium chloride & $9.0 \mathrm{mmol} / \mathrm{L}$ \\
\hline Magnesium chloride & $4.0 \mathrm{mmol} / \mathrm{L}$ \\
\hline Calcium chloride & $0.015 \mathrm{mmol} / \mathrm{L}$ \\
\hline Histidine & $180.0 \mathrm{mmol} / \mathrm{L}$ \\
\hline Tryptophan & $2.0 \mathrm{mmol} / \mathrm{L}$ \\
\hline Ketoglutarate & $1.0 \mathrm{mmol} / \mathrm{L}$ \\
\hline Mannitol & $30.0 \mathrm{mmol} / \mathrm{L}$ \\
\hline pH & $7.02-7.20$ at $25^{\circ} \mathrm{C}\left(77.0^{\circ} \mathrm{F}\right)$ \\
& $7.4-7.45$ at $4^{\circ} \mathrm{C}\left(39.2^{\circ} \mathrm{F}\right)$ \\
& Osmolality: $310 \mathrm{mosmol} / \mathrm{Kg}$ \\
\hline
\end{tabular}

will be administered through a single dose of $20 \mathrm{~mL} / \mathrm{kg}$ (maximum of $1000 \mathrm{~mL}$ for patients weighing over $50 \mathrm{~kg}$ ), usually with a delivery temperature of $4^{\circ} \mathrm{C}$, system pressure of 100-200 $\mathrm{mm} \mathrm{Hg}$, and an administration flow of 200-300 mL/min. ${ }^{1}$ If necessary, additional doses will be infused after $90 \mathrm{~min}$ of the initial one. ${ }^{1}$

The nature of cardioplegic solutions del Nido and Custodiol is distinct in terms of their vehicles (blood and crystalloid, respectively) and electrolytic compositions (extracellular and intracellular, respectively), differing in the cardiac arrest mechanism (del Nido causes a depolarising arrest, while Custodiol causes a hyperpolarising arrest).

\section{Outcomes}

\section{Primary outcome}

The primary outcome will be to assess myocardial protection between cardioplegic solutions Custodiol, del Nido and modified del Nido using the serum levels of cardiac enzymes, including creatine kinase (CK), CK isoenzyme MB (CK-MB) and troponin in the immediate postoperative period as well as 12 hours and 24 hours after the CPB.

\section{Secondary outcomes}

The secondary outcomes include:

\begin{tabular}{ll}
\hline Table 2 Compositions of del Nido cardioplegia \\
\hline del Nido cardioplegia (1:4) \\
\hline Composition \\
\hline Plasma-Lyte A or Lactated Ringer's solution \\
\hline Sodium bicarbonate $1 \mathrm{mEq} / \mathrm{mL}$ & $1000 \mathrm{~mL}$ \\
\hline Mannitol (20\%) & $13 \mathrm{~mL}$ \\
\hline Magnesium sulfate (50\%) & $16.3 \mathrm{~mL}$ \\
\hline Lidocaine (1\%) & $4 \mathrm{~mL}$ \\
\hline Potassium chloride $2 \mathrm{mEq} / \mathrm{mL}$ & $13 \mathrm{~mL}$ \\
\hline
\end{tabular}

Dose $20 \mathrm{~mL} / \mathrm{kg}$ with a maximum dose of $1000 \mathrm{~mL}$ for patients weighing more than $50 \mathrm{Kg}$ 


\begin{tabular}{|c|c|c|c|c|c|c|}
\hline \multirow[b]{3}{*}{\begin{tabular}{|l|} 
Time point \\
\end{tabular}} & \multicolumn{6}{|c|}{ Study Period } \\
\hline & \multirow{2}{*}{$\begin{array}{c}\text { Enrolment } \\
\text { Interviews }\end{array}$} & \multirow{2}{*}{$\begin{array}{c}\text { Allocation } \\
\text { Following } \\
\text { confirmation } \\
\text { of eligibility } \\
\text { to day of } \\
\text { surgery }\end{array}$} & \multicolumn{3}{|c|}{ Post-allocation } & \multirow{2}{*}{ 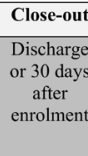 } \\
\hline & & & $\begin{array}{l}\text { Day of } \\
\text { surgery }\end{array}$ & $\begin{array}{c}0-24 \mathrm{~h} \\
\text { Post op }\end{array}$ & \begin{tabular}{|c} 
Post op \\
onwards \\
until \\
discharge
\end{tabular} & \\
\hline \multicolumn{7}{|l|}{\begin{tabular}{|l|} 
Enrolment \\
\end{tabular}} \\
\hline \begin{tabular}{|l|} 
Eligibility screen \\
\end{tabular} & $\mathrm{X}$ & & & & & \\
\hline Informed consent & $\mathrm{X}$ & & & & & \\
\hline \begin{tabular}{|l|} 
Demographic data \\
\end{tabular} & $\mathrm{x}$ & & & & & \\
\hline \begin{tabular}{|l} 
Anthropometric data \\
\end{tabular} & $\mathrm{x}$ & & & & & \\
\hline \begin{tabular}{|l} 
Clinical data \\
\end{tabular} & $\mathrm{X}$ & & & & & \\
\hline \begin{tabular}{|l} 
Allocation (randomization) \\
\end{tabular} & & $\mathrm{x}$ & & & & \\
\hline \multicolumn{7}{|l|}{\begin{tabular}{|l|} 
Interventions \\
\end{tabular}} \\
\hline \begin{tabular}{|l|l|} 
Custodiol \\
\end{tabular} & & & $\mathrm{x}$ & & & \\
\hline \begin{tabular}{|l} 
del Nido \\
\end{tabular} & & & $\mathrm{x}$ & & & \\
\hline \begin{tabular}{|l|} 
del Nido modificado \\
\end{tabular} & & & $\mathrm{x}$ & & & \\
\hline \multicolumn{7}{|l|}{\begin{tabular}{|l} 
Assessments \\
\end{tabular}} \\
\hline \begin{tabular}{|l|} 
Baseline variables \\
\end{tabular} & & $\mathrm{x}$ & $\mathrm{x}$ & & & \\
\hline \begin{tabular}{|l|} 
Peri-procedural variables \\
\end{tabular} & & & $\mathrm{x}$ & $\mathrm{x}$ & $\mathrm{x}$ & \\
\hline \begin{tabular}{|l|l} 
Clinical outcomes \\
\end{tabular} & & & $\mathrm{x}$ & $\mathrm{x}$ & $\mathrm{x}$ & $\mathrm{x}$ \\
\hline \begin{tabular}{|l|l} 
Echocardiogram \\
\end{tabular} & $\mathrm{X}$ & & & & & $\mathrm{X}$ \\
\hline
\end{tabular}

Figure 2 Standard Protocol Items: Recommendations for Interventional Trials (SPIRIT) checklist. Enrolment, interventions and assessments.

1. Assessments of additional myocardial protection measures: incidence of ventricular fibrillation requiring electrical defibrillation after aortic cross-clamp removal, postoperative changes in the left ventricular ejection fraction (LVEF) and in the ventricular septal function, blood gas analysis, duration of inotrope or vasopressor requirement and requirement for intra-aortic balloon pump (IABP) support.

2. Intraoperative outcomes: total volume of cardioplegia and number of doses, total aortic cross-clamp time and CPB.

3. Clinical outcomes: ICU stay, prolonged ventilation (over 24 hours), the incidence of postoperative atrial fibrillation (AF) or flutter, acute MI, mortality and blood products transfusion.

4. Comparisons among cardioplegic solutions regarding the prediction of major cardiovascular events in adult patients undergoing cardiac surgery.

\section{Participant timeline}

The schedule for enrolment, interventions and assessments is outlined in figure 2. The recruitment of study participants began in 15 July 2020 .

\section{Sample size}

The sample size calculation was performed using the G-Power program V.3.1.9.4. Considering an effect $\mathrm{f}=0.466$ on troponin levels based on the study by Talwar $e t a{ }^{24}$ maintaining a $95 \%$ statistical power and a $5 \%$ significance, it would be necessary to investigate 75 patients. Thus, with an additional $20 \%$ to account for potential losses, 90 individuals will be selected for the study, with 30 randomised for each group.

\section{Recruitment and allocation}

Candidate patients for cardiac surgery will be identified at the point of referral or from the inpatient waiting list by the clinical team and approached by a research team member about participation in the study. After consent, the eligible patients will be randomised to receive Custodiol, del Nido or modified del Nido following confirmation of eligibility.

\section{Randomisation}

The patients will be randomised in blocks to receive the del Nido, modified del Nido or Custodiol solutions during $\mathrm{CPB}$, with a sequence generated by website randomizer. org and the numbers being placed in opaque envelopes and sealed individually.

\section{Blinding}

On the same day of surgery and before anaesthetic induction, the perfusionist will receive the opaque and sealed envelope indicating the cardioplegic solution to be prepared and administered according to its particularities.

All the patients, anaesthetists, echocardiographers, nurses and laboratory staff will be blinded to the type of intervention.

Since the Custodiol infusion requires an administration time and interval between doses different from the del Nido solution, the surgical team will only be blinded to the intervention with del Nido or modified del Nido, besides not participating in the analysis of the results to avoid measurement biases. There is no possibility of standardising the volume of the solutions, administration times and interval between doses due to the potential increase in risk for the patients.

After surgery, all patients will be transferred to the ICU, intended for the recovery of patients submitted to cardiac surgery, and monitored by a team with postoperative expertise in the specialty, according to the standard institutional protocols, blinded to the type of cardioplegia administered during the surgery. After discharge from the ICU, these patients will be transferred to the postoperative cardiology unit, where they will be managed until hospital discharge by the team responsible, according to standard protocols, also blinded to the type of intervention.

Moreover, the lead investigator, who will identify the outcomes and perform the statistical analyses, will be blinded to the type of intervention used in each case.

All deaths or complications, be they cardiovascular or not, reported during the conduction of the study will be analysed. All researchers involved in the adjudication process will remain blind to the allocation of the patients regarding the type of intervention. The adjudicated data will be used in the final analysis of safety and efficacy.

\section{Data collection methods}

\section{Baseline assessments}

The baseline interviews pertaining to demographic, anthropometric and clinical data using a standardised questionnaire will be recorded during the enrolment process, following consent and before the randomisation. Demographic data include age, gender and education 
level. Anthropometric data include weight, height and body mass index. Clinical data include diseases, treatment information, medical history and medications at the time, as well as preoperative laboratory work, an echocardiogram and coronary angiography. Venous blood samples will be collected to measure the lipid profile, blood count, serum electrolyte levels $(\mathrm{Na}+, \mathrm{K}+)$, blood gas analysis, $\mathrm{C}$ reactive protein, creatinine, urea and glucose.

Diabetes mellitus will be defined as a patient's self-report of a physician's diagnosis or use of hypoglycaemic agents or insulin. Three blood pressure measurements will be taken using a validated automatic device according to guidelines. ${ }^{25}$ Hypertension will be defined as the average of the last two among three blood pressure measurements greater than $140 / 90 \mathrm{~mm} \mathrm{Hg}$, or the use of blood pressurelowering medication.

The estimated surgical risk will be calculated before the randomisation by the EuroSCORE (European System for Cardiac Operative Risk Evaluation), Society of Thoracic Surgery (STS) Score and Ambler, available online: http:/ / www.euroscore.org; http://riskcalc.sts.org/stswebriskcalc/calculate and https://wwwthecalculatorco/health/ Heart-Valve-Surgery-Risk-Calculator-1107html. Note: the STS Score allows calculating isolated surgeries for aortic and mitral valve replacement; combined surgery cannot be included in the STS, only in the Ambler.

\section{Laboratory assessment}

Arterial blood will be collected from patients to perform serum troponin and CK-MB tests, in addition to blood count, glucose, C reactive protein, lactate, and blood gas measurements, at four scheduled times: before anaesthesia induction, and 2 hours, 12 hours and 24 hours after the discontinuation of $\mathrm{CPB} .^{9}$

Laboratory measurements will be performed by the clinical diagnostic laboratory of the hospital, and the devices will be checked and calibrated as part of the daily laboratory practice. The laboratory staff will be unaware of the groups to which each patient is assigned.

\section{Echocardiogram}

The calculated LVEF and ventricular septal function will be assessed using transthoracic echocardiography at two different times: during enrolment and on the seventh postoperative day. The echocardiography exams will be performed by the hospital diagnostic service with standardised equipment and techniques for all patients.

\section{Clinical outcomes}

A predefined team of researchers will monitor clinical or surgical outcomes during the transoperative period and the ICU stay.

Other parameters of cross-clamp time, CPB time, the total volume of cardioplegia and number of doses, mechanical ventilation, haemodynamic parameters, transfusion of blood and blood products, the requirement for IABP support and the use of inotropes will be recorded.
Outcomes after surgical treatment defined before the analysis, including mortality, MI, stroke, the incidence of blood products transfusion, as well as prolonged ventilation (over 24hours) and ICU stay, will be compared among groups. In addition, we will compare, among the groups, the proportion of patients experiencing postoperative new-onset $\mathrm{AF}$ or flutter requiring treatment, heart block and ventricular tachycardia or fibrillation requiring cardioversion or intravenous amiodarone.

MI will be diagnosed by increasing cardiac biomarkers in the presence of symptoms or ECG abnormalities suggestive of ischaemia. ${ }^{26} 27$

Strokes will be diagnosed by CT scanning and compatible clinical findings, besides medical record reviews. ${ }^{28} 29$

Deaths will be classified according to the Atherosclerosis Risk in Communities Study protocol. ${ }^{26}$

\section{Data management}

The data will be managed by study investigators using a predesigned data collection form and SPSS files V.26.0 (IBM) with double data entry.

Data checks will be performed regularly to ensure data quality. Patients will be identified by codes to ensure their anonymity, and only the authors involved in the trial will have access to their full identification details.

The total number of patients meeting the eligibility criteria of the study will be recorded, as well as the number of patients agreeing or not to participate in the study, the number of patients assigned to each branch of the study, the number of patients attending all sessions, the number of patients included in the final analysis and the number of withdrawals.

\section{Statistical analysis}

Quantitative variables will be described by means and SDs in cases of symmetrical distributions or by medians and IQRs in cases of asymmetric distributions. Qualitative variables will be described by the absolute and relative frequencies.

To compare means among groups, a one-way analysis of variance with Tukey's post hoc analysis will be applied. In case of asymmetry, the Kruskal-Wallis test complemented by the Dunn test shall be used. In order to compare proportions among groups, Pearson's $\chi^{2}$ test complemented by the adjusted residual test shall be applied.

A generalised estimating equations model will be used to compare the parameters over the follow-up time among the groups, complemented by the Bonferroni test. A linear model will be used for variables with normal distribution and the gamma model for those with asymmetric distribution.

The significance level adopted will be $5 \%$, and the data will be analysed using the SPSS V.26.0.

\section{Safety and data monitoring}

Although the natures of the del Nido and Custodiol cardioplegic solutions are different regarding their cardiac arrest mechanisms, both are associated with safe 
single-dose administration and capable of preserving the myocardium for a prolonged period during ischaemia in $\mathrm{CPB}^{3810}$

The outcomes will be audited by the lead investigator every five interventions or earlier if serious adverse postoperative events are recorded.

Adverse events will be evaluated by the study investigators, who will decide to stop the study early if there is a clinically relevant increased risk.

All data will be evaluated by at least two authors independently, with quality control on data entry to verify amplitude and consistency. For quality control of the team's performance, $20 \%$ of the protocols will be randomly selected for review by the lead investigator.

\section{ETHICS AND DISSEMINATION}

Registered under no. 4.029.545, this study protocol and its related documents were approved by the Research Ethics Committee of the Hospital Nossa Senhora da Conceição, which is accredited by the Office of Human Research Protections as an institutional review board. This study will be conducted following the 1964 Declaration of Helsinki and its later amendments or comparable ethical standards. All participants will provide informed consent (online supplemental file 2). During the preclinical assessment, investigators will explain all study details. When it is not possible to obtain consent for whatever reason, the patient cannot be involved. It will be ensured to the volunteer the right not to participate, without this representing any prejudice to their care within the institution.

Any modifications that could impact the conduction of the study, such as changes to the objective, design, sample or significant administrative aspects, will require a formal request for amendment with the institutional research ethics committee.

Regarding privacy and confidentiality, the preservation of patient anonymity and the use of data obtained in the research only for the purpose of the project are guaranteed.

The findings of this study will be submitted to a peerreviewed journal for publication and presented at relevant medical conferences.

\section{Data availability statement}

The datasets generated and used during this study are available from the corresponding author on reasonable request.

The technical appendix, statistical code and dataset may be available on the completion of the trial from the Dryad or a similar repository.

\section{DISCUSSION}

\section{Potential impact and significance of the clinical trial}

This project was developed through extensive bibliographic research on a subject of great importance in daily surgical practice. The interpretation of the results published in several studies enabled the development of this well-structured protocol.

Optimal myocardial protection during cardiac surgery is one of the main components of a successful procedure. Since the $1950 \mathrm{~s},{ }^{30}{ }^{31}$ many strategies have continuously been developed to improve myocardial protection and prevent further ischaemic injury. Over the past few decades, there have been no standardised guidelines for using cardioplegic solutions, and prolonged-action or single-dose solutions seem closer than expected to an ideal solution.

Talwar et $a l^{24}$ randomised 100 paediatric patients submitted to elective surgical correction of Fallot's tetralogy to receive cardioplegic solutions del Nido or Custodiol. The first was associated with the better preservation of the cardiac index, shorter mechanical ventilation time, shorter stay at the ICU and the hospital, better cardiac output, lower inotropic scores and lower release of troponin-I. Electronic microscopy evinced less myocardium oedema and better preservation of the myofibrillar architecture and glycogen storage in the group that received del Nido. In another clinical trial, Mehrabanian $e t a l^{32}$ randomised 40 patients to receive one of these cardioplegic solutions, concluding that both offer effective and similar cardioprotective properties during CPB in adults. The authors did not show any significant differences in CPB time, cross-clamp duration, urine output, chest tube drainage, duration of mechanical ventilation, ICU stay, mean arterial pressure, LVEF, use of blood products and inotropic support. Blood chemistry parameters and blood gas analysis revealed a similar trend between the groups except for sodium levels after cardioplegia and the end of CPB, potassium levels after cardioplegia, and bicarbonate anions at the end of the bypass, with lower results in the Custodiol group compared with the del Nido group.

In several studies, patients who received del Nido had lower ventricular fibrillation rates after aortic cross-clamp removals than those who received conventional blood cardioplegia, ${ }^{491233-35}$ in addition to lower CK-MB values, ${ }^{34}$ lower glucose levels during $\mathrm{CPB}^{35-37}$ or less use of postoperative intravenous insulin, ${ }^{34}$ less need for transoperative inotropic support and lower troponin levels, ${ }^{9}$ suggesting better myocardial protection with this solution.

The base solution for the del Nido cardioplegia is Plasma-Lyte A, which is unfortunately unavailable in many countries, precluding many cardiac centres from using del Nido cardioplegia with their typical base solution. Kantathut et $a l^{17}$ published an observational study that evaluated myocardial preservation and clinical outcomes when using the lactated Ringer's solution as the base solution for the del Nido cardioplegia compared with the standard blood cardioplegia strategy (St. Thomas cardioplegia). The group that received the modified del Nido stayed at the ICU and the hospital for a shorter time, showing a lower use of inotropic support and a lower incidence of postoperative fibrillation or flutter. These results 
make the lactated Ringer's solution seem like an excellent alternative to Plasma-Lyte A in the del Nido formulation for adult patient surgeries.

Hence, the del Nido cardioplegic solution seems highly efficient both for myocardial protection and regarding the economic aspects. However, extensive literature comparing its use with that of Custodiol does not exist, especially with the addition of the lactated Ringer's solution to its formulation. Therefore, it is necessary to conduct prospective and randomised studies to prove the hypothesis of the superiority of this cardioplegia over the others in terms of myocardial protection in adult patients. $^{112}$

\section{Clinical applicability}

The results obtained in the proposed clinical trial may provide subsidies via publication to implement and insert clinical protocols in many institutions, increasing safety and reducing expenses. In addition, despite being performed in a single centre, the clinical practice of our hospital reflects the standard of practice in our country and may contribute to the international assessment of the cardioplegic solution with the best profile for reducing myocardial injury.

\section{Twitter Adriana Silveira Almeida @adriana25504}

Acknowledgements This study would not have been possible without the commitment and enthusiasm of all professionals and patients within the Cardiothoracic Surgery Division, surgical centre, intensive care unit and clinical laboratory at the Hospital Nossa Senhora da Conceição. Also, we thank the Board of the Hospital for providing the opportunity to carry out this project at the Institution, with clear individual, collective and institutional benefits, especially because it is one of the largest reference tertiary public hospitals in the country.

Contributors ASA, ROC, FA, LK, KBL, RSD, JR and RAWR contributed to the conceptualisation, study design, proposal development, methodology, validation, resources, writing-original draft, writing-review, editing and visualisation. ASA is also responsible for data curation and supervision. KBL and RSD are also involved in recruitment and data collection. EIW and ARR are involved in the clinical followup in the preoperative and postoperative period, as well as in requesting and reviewing tests necessary for research at this stage. All authors have read and approved the final version to be published and agreed to be accountable for all aspects of the work.

Funding The authors have not declared a specific grant for this research from any funding agency in the public, commercial or not-for-profit sectors.

Competing interests None declared.

Patient consent for publication Not required.

Provenance and peer review Not commissioned; externally peer reviewed.

Supplemental material This content has been supplied by the author(s). It has not been vetted by BMJ Publishing Group Limited (BMJ) and may not have been peer-reviewed. Any opinions or recommendations discussed are solely those of the author(s) and are not endorsed by BMJ. BMJ disclaims all liability and responsibility arising from any reliance placed on the content. Where the content includes any translated material, BMJ does not warrant the accuracy and reliability of the translations (including but not limited to local regulations, clinical guidelines, terminology, drug names and drug dosages), and is not responsible for any error and/or omissions arising from translation and adaptation or otherwise.

Open access This is an open access article distributed in accordance with the Creative Commons Attribution Non Commercial (CC BY-NC 4.0) license, which permits others to distribute, remix, adapt, build upon this work non-commercially, and license their derivative works on different terms, provided the original work is properly cited, appropriate credit is given, any changes made indicated, and the use is non-commercial. See: http://creativecommons.org/licenses/by-nc/4.0/.

\section{ORCID iDs}

Adriana Silveira Almeida http://orcid.org/0000-0001-5639-9768

Rafael Oliveira Ceron http://orcid.org/0000-0002-3517-1526

Fernando Anschau http://orcid.org/0000-0002-2657-5406

Luciane Kopittke http://orcid.org/0000-0002-6606-7756

Kathize Betti Lira http://orcid.org/0000-0002-4479-3319

Renan Senandes Delvaux http://orcid.org/0000-0002-6368-5866

Juarez Rode http://orcid.org/0000-0002-8430-7514

Rafael Antônio Widholzer Rey http://orcid.org/0000-0002-3656-7573

Estefânia Inês Wittke http://orcid.org/0000-0002-2384-6186

Alfeu Roberto Rombaldi http://orcid.org/0000-0001-9377-9698

\section{REFERENCES}

1 Sanetra K, Pawlak I, Cisowski M. Del Nido cardioplegia - what is the current evidence? Kardiochir Torakochirurgia Pol 2018;15:114-8.

2 Vivacqua A, Robinson J, Abbas AE, et al. Single-dose cardioplegia protects myocardium as well as traditional repetitive dosing: a noninferiority randomized study. J Thorac Cardiovasc Surg 2020;159:1857-63.

3 Siddiqi S, Blackstone EH, Bakaeen FG. Bretschneider and del NIDO solutions: are they safe for coronary artery bypass grafting? if so, how should we use them? J Card Surg 2018;33:229-34.

4 Buel ST, Striker CW, O'Brien JE. Del NIDO versus St. Thomas cardioplegia solutions: a single-center retrospective analysis of post Cross-Clamp defibrillation rates. J Extra Corpor Technol 2016;48:67-70.

5 Bretschneider HJ, Hübner G, Knoll D, et al. Myocardial resistance and tolerance to ischemia: physiological and biochemical basis. $J$ Cardiovasc Surg 1975;16:241-60.

6 Groenewoud AF, Buchholz B, Gubernatis F, et al. First results of the multicenter study of HTK protection for kidney transplants. Transplant Proc 1990;22:2212.

7 Hölscher M, Groenewoud AF. Current status of the HTK solution of Bretschneider in organ preservation. Transplant Proc 1991;23:2334-7.

8 Edelman JJB, Seco M, Dunne B, et al. Custodiol for myocardial protection and preservation: a systematic review. Ann Cardiothorac Surg 2013;2:717-28.

9 Ad N, Holmes SD, Massimiano PS, et al. The use of del NIDO cardioplegia in adult cardiac surgery: a prospective randomized trial. $J$ Thorac Cardiovasc Surg 2018;155:1011-8.

10 Matte GS, del Nido PJ. History and use of del Nido cardioplegia solution at Boston children's Hospital. J Extra Corpor Technol 2012;44:98-103.

11 Ota T, Yerebakan H, Neely RC, et al. Short-term outcomes in adult cardiac surgery in the use of del Nido cardioplegia solution. Perfusion 2016;31:27-33.

12 Guajardo Salinas GE, Nutt R, Rodriguez-Araujo G. Del NIDO cardioplegia in low risk adults undergoing first time coronary artery bypass surgery. Perfusion 2017;32:68-73.

13 Kim K, Ball C, Grady P, et al. Use of del Nido cardioplegia for adult cardiac surgery at the Cleveland clinic: perfusion implications. J Extra Corpor Technol 2014;46:317-23.

14 Mongero LB. Del Nido Cardioplegia-Not just kids stuff. J Extra Corpor Technol 2016;48:P25-8.

15 Najjar M, George I, Akashi H, et al. Feasibility and safety of continuous retrograde administration of del Nido cardioplegia: a case series. J Cardiothorac Surg 2015;10:176.

16 Yerebakan H, Sorabella RA, Najjar M, et al. Del Nido cardioplegia can be safely administered in high-risk coronary artery bypass grafting surgery after acute myocardial infarction: a propensity matched comparison. J Cardiothorac Surg 2014;9:141.

17 Kantathut N, Cherntanomwong P, Khajarern S, et al. Lactated Ringer's as a base solution for del NIDO cardioplegia. J Extra Corpor Technol 2019;51:153-9.

18 An KR, Rahman IA, Tam DY, et al. A systematic review and metaanalysis of del NIDO versus conventional cardioplegia in adult cardiac surgery. Innovations 2019;14:385-93.

19 Orak Y, Kocarslan A, Boran OF, et al. Comparison of the operative and postoperative effects of del Nido and blood cardioplegia solutions in cardiopulmonary bypass surgery. Braz J Cardiovasc Surg 2020;35:689-96.

20 Pérez-Andreu J, Fernández-Doblas J, Sao Avilés A, et al. Myocardial protection in the arterial switch operation: Custodiol versus cold blood cardioplegia. Interact Cardiovasc Thorac Surg 2020;30:136-43.

21 George G, Varsha AV, Philip MA, et al. Myocardial protection in cardiac surgery: del Nido versus blood cardioplegia. Ann Card Anaesth 2020;23:477-84. 
22 Chan A-W, Tetzlaff JM, Altman DG, et al. SPIRIT 2013 statement: defining standard protocol items for clinical trials. Ann Intern Med 2013;158:200-7.

23 Schulz KF, Altman DG, Moher D, et al. CONSORT 2010 statement: updated guidelines for reporting parallel group randomized trials. Ann Intern Med 2010;152:726-32.

24 Talwar S, Chatterjee S, Sreenivas V, et al. Comparison of de Nido and histidine-tryptophan-ketoglutarate cardioplegia solutions in pediatric patients undergoing open heart surgery: A prospective randomized clinical trial. J Thorac Cardiovasc Surg 2019;157:1182-92.

25 Williams B, Mancia G, Spiering W, et al. 2018 ESC/ESH guidelines for the management of arterial hypertension. Eur Heart $J$ 2018;39:3021-104.

26 The ARIC Investigators. The Atherosclerosis risk in communities (ARIC) study: design and objectives. The ARIC Investigators. Am J Epidemiol 1989;129:687-702.

27 Thygesen K, Alpert JS, Jaffe AS, et al. Fourth universal definition of myocardial infarction (2018). J Am Coll Cardiol 2018;72:2231-64.

28 Powers WJ, Rabinstein AA, Ackerson T, et al. Guidelines for the early management of patients with acute ischemic stroke: 2019 update to the 2018 guidelines for the early management of acute ischemic stroke: a guideline for healthcare professionals from the American heart Association/American stroke association. Stroke 2019;50:e344-418. Erratum in: Stroke 2019;50(12):e440-e441.

29 Hemphill JC, Greenberg SM, Anderson CS, et al. Guidelines for the management of spontaneous intracerebral hemorrhage: a guideline for healthcare professionals from the American heart Association/ American stroke association. Stroke 2015;46:2032-60.
30 Ferguson ZG, Yarborough DE, Jarvis BL, et al. Evidence-based medicine and myocardial protection--where is the evidence? Perfusion 2015;30:415-22.

$31 \mathrm{Li} \mathrm{Y}$, Lin H, Zhao Y, et al. Del NIDO cardioplegia for myocardial protection in adult cardiac surgery: a systematic review and metaanalysis. Asaio J 2018;64:360-7.

32 Mehrabanian MJ, Dehghani Firoozabadi M, Ahmadi Tafti SH, et al. Clinical outcomes and electrolyte balance factors in complex cardiac operations in adults; del Nido ${ }^{\circledR}$ versus Custodiol $₫$ cardioplegia solutions: a randomized controlled clinical trial. Iran Red Crescent Med J 2018;20:e64648.

$33 \mathrm{Kim}$ JS, Jeong JH, Moon SJ, et al. Sufficient myocardial protection of del Nido cardioplegia regardless of ventricular mass and myocardial ischemic time in adult cardiac surgical patients. $J$ Thorac Dis 2016;8:2004-10.

34 Vistarini N, Laliberté E, Beauchamp P, et al. Del Nido cardioplegia in the setting of minimally invasive aortic valve surgery. Perfusion 2017;32:112-7.

35 Misra S, Srinivasan A, Jena SS, et al. Myocardial protection in adult cardiac surgery with del NIDO versus blood cardioplegia: a systematic review and meta-analysis. Heart Lung Circ 2021;30:642-55.

36 Timek T, Willekes $\mathrm{C}$, Hulme $\mathrm{O}$, et al. Propensity matched analysis of del Nido cardioplegia in adult coronary artery bypass grafting: initial experience with 100 consecutive patients. Ann Thorac Surg 2016;101:2237-41.

37 Ziazadeh D, Mater R, Himelhoch B. Single-dose del Nido cardioplegia in minimally invasive aortic valve surgery. Semin Thorac Cardiovasc Surg 2017;S1043-0679:30287-3. 